\title{
Дослідження міцності елементів конструкції функціонально-транспортуючих мобільних засобів
}

\author{
А.В. Бабійํㅜ, М.В. Бабій ${ }^{2}$ \\ Тернопільський національний технічний університет \\ імені Івана Пулюя (м.Тернопіль, Україна) \\ 1 ORCID: 0000-0001-6198-0100, email: ababiy@ukr.net \\ 2 ORCID: 0000-0002-5231-0508
}

\begin{abstract}
В даній роботі проведено аналіз конструктивних особливостей технологічних машин, які однією із своїх функцій мають транспортування води чи робочих рідин. Проблема, що часто виникає з такими транспортними засобами - це механічне руйнування резервуара. В проведеному дослідженні вибрано одну із груп таких машин, які транспортують циліндричні резервуари. Особливістю конструкції представлених баків $є$ те, що вони обперті на опори у вигляді ложементів і притягнуті до них гнучкими бандажами. Щоб з'ясувати причину руйнування вказаних конструкцій, спочатку потрібно проаналізувати їх напружено-деформований стан. Цього можна досягнути лише в тому випадку, якщо є відомим навантаження на саму обичайку бака, тобто його циліндричну частину. За аналізом літературних джерел таке навантаження може бути розділеним на кілька складових: від тиску рідини на стінки резервуару, сюди може додаватися ще надлишковий тиск; від дії опор (контактний тиск); і аналогічно від затягування бандажів. Задача визначення напружено-деформованого стану бака технологічної машини є досить складною, ії вирішення повинно бути поетапним. Тому в даній роботі розглядаються математичні моделі навантаження від затягування бандажів при закріплені бака до опор як локальна задача щодо визначення навантаження в цілому. Отримавши кінцеві вирази для контактного тиску бандажа на обичайку бака, а також вирази від інших складових навантаження, проводять процедуру розвинення даних функцій в тригонометричні ряди. Після чого отримані залежності інтегрують в загальну розрахункову модель для визначення напружено-деформованого стану обичайки бака технологічної машини. А в кінцевому результаті, це дозволить вибирати задовільний швидкісний режим транспортування даними машинами рідини, враховуючи динаміку процесу.
\end{abstract}

Ключові слова: транспортування, бак, механічне руйнування, бандаж, контактний тиск, математичні моделі.

Постановка проблеми. Виробництво сільськогосподарської продукції в сучасних умовах $€$ неможливим без використання мобільних енергетичних засобів чи технологічних машин на їх основі. Надійність та довговічність таких машин це одна з основних умов отримання високих врожаїв через своєчасність виконання технологічних операцій при вирощуванні будь-якої культури.

Мобільні сільськогосподарські машини часто суміщають операції транспортування і безпосереднього виконання технологічного процесу. До таких машин можна віднести обприскувачі, заправники-транспортувальники рідин тощо. Дані транспортні засоби повинні надійно переміщатися шляхами, а також мати герметичні баки для транспортування рідин. Але як показує практика, що резервуари, в яких знаходяться робочі рідини, часто виходять з ладу через механічні пошкодження. Такі проблеми виникають внаслідок перевищення допустимих напружень в обичайці бака через неправильне їх закріплення на опорах та зайве затягування бандажами.
Аналіз досліджень і публікацій. Питанням надійності баків сільськогосподарських обприскувачів присвячено багато праць вчених, зокрема, Рибака Т.І. [1,2]; розвиток теоретичних основ для дослідження міцності обичайок баків, впливу на їх напружено-деформований стан способу закріплення розвинуті в працях Сухорольського М.А., Пелеха Б.Л. [3,4].

Всі автори практично є одностайними в тому, що діюче навантаження на обичайку бака потрібно розділяти на окремі складові, що описуються адекватними математичними моделями, які можна реалізувати за прийнятою теорією оболонок.

Мета досліджень. Розглянути локальну задачу при дослідженні напружено-дефрормованого стану обичайки бака мобільної сільськогосподарської машини, яка полягає в аналізі виникнення додаткових навантажень від затягування бандажів при закріпленні бака до опори.

Запропонувати моделі дії вказаних кріпильних елементів на обичайку бака для введення їх 
в загальну модель щодо визначення напруженодеформованого стану бака в цілому.

Результати досліджень. Покажемо деякі конструкції функціонально-транспортуючих мобільних засобів, які використовуються у сільськогосподарському виробництві, рис. 1 [5].

Як видно з проведеного аналізу, що однією 3 основних складових розглядуваних мобільних машин $€$ циліндричні резервуари, які обперті на опорах у вигляді ложементів та притягнуті бандажами.
Обичайки баків піддаються складному навантаженню у вигляді дії ваги рідини, внутрішнього тиску (в окремих випадках), тиску бандажів та опор. Для визначення напружено-деформованого стану таких резервуарів необхідно скористатися однією із теорій оболонок, де в якості навантаження ввести розглядувані складові. Задача $€$ доволі складною через багатогранність навантаження, що описуватиметься рядом математичних моделей, які з максимальною достовірністю описуватимуть реальне діюче навантаження.

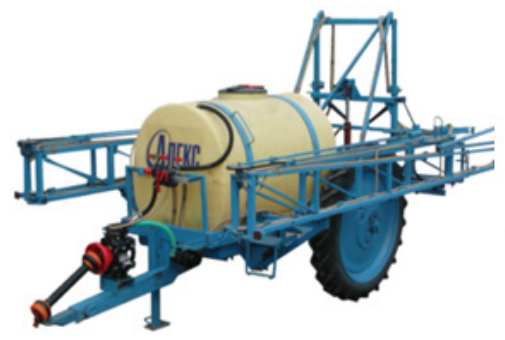

A

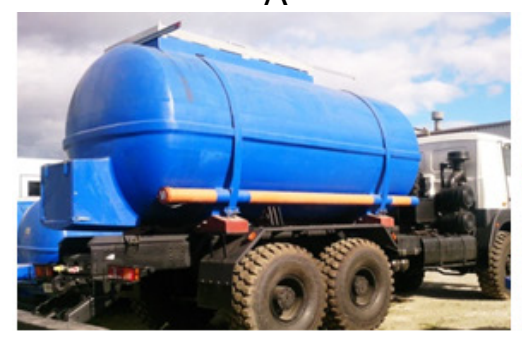

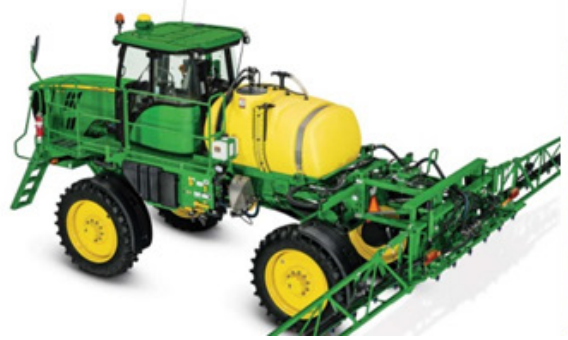

б

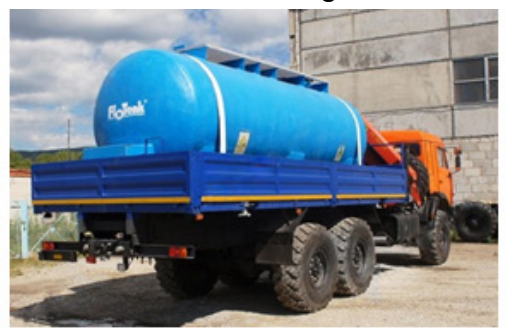

Д

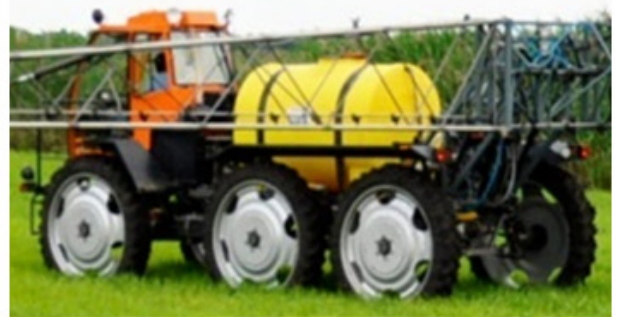

B

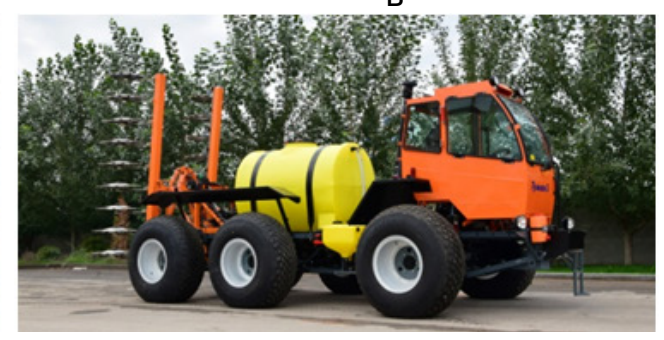

e

Рис. 1. Мобільні технологічні машини з баками, що приєднані бандажами

а - причіпний обприскувач польовий малооб'ємний штанговий “Алекс”; б - самохідний обприскувач John Deere R4030; в - самохідний обприскувач Туман 2 на вузьких колесах; г - склопластикові автоцистерни для транспортування будь-яких рідин в т.ч. агресивних; д - автоцистерна для води і молока від компанії «Флотенк»; е - мультиінжектор на базі Туман 2

Виконуючи локальне дослідження, проведемо моделювання дії бандажів на обичайку циліндричного бака мобільної технологічної машини, що використовується в аграрному секторі, наприклад самохідному чи причіпному обприскувачі.

Перша складова загального навантаження на обичайку бака - дія стягуючих бандажів. Побудуємо варіанти математичних моделей їх дії для інтегрування в загальний розв'язок задачі про напружено-деформований стан [2]. Представимо загальну розрахункову схему взаємодії бандажа з поверхнею обичайки бака, рис. 2 [1,2].

Відповідно до рис. 2 бандаж 1 взаємодіє 3 обичайкою бака 2 вздовж зони контакту шириною $2 b_{0}$ та довжиною обхвату $2 R_{0}\left(\pi-\phi_{0}\right)$. Затягують бандаж зусиллям $N_{0}$. Контактний тиск - це функція $q\left(\alpha_{1}, \alpha_{2}\right)$, де $\alpha_{1}-$ координата вздовж осі циліндра; $\alpha_{2}$ - колова координата, яка визначається як $\alpha_{2}=R_{0} \phi$. Тут $R_{0}-$ радіус кривизни бандажа в зоні контакту з обичайкою; $\phi$ - змінна кутова координата, рис. 2.

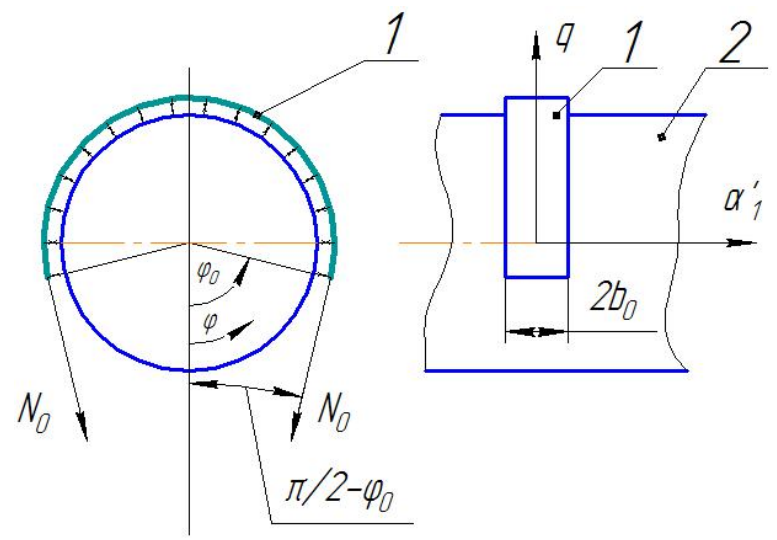

Рис. 2. Загальна розрахункова схема взаємодії бандажа з поверхнею обичайки бака: 1 - бандаж; 2 - обичайка бака 
Розглянемо випадок, коли контактний тиск змінюється за гіперболічним косинусом вздовж ширини контакту бандажа та постійний по його довжині.

$$
q\left(\alpha_{1}^{\prime}, \alpha_{2}\right)=\operatorname{Ach}\left(a_{0} \alpha_{1}^{\prime}\right),
$$

де $\alpha_{1}^{\prime}$ - локальна координата, яка визначається в межах ширини бандажа, тобто $-b_{0} \leq \alpha_{1}^{\prime} \leq b_{0} ; a_{0}$ - задана величина; $A$ - невідомий коефріцієнт.

Вважаючи, що резервуар на транспортному засобі закріплено симетрично, зусилля які діють на бандаж відносно осі навантаження також будуть симетричними. Проектуючи їх на вертикальну вісь, отримаємо

$$
\begin{gathered}
-2 N_{0} \cos \left(\frac{\pi}{2}-\phi_{0}\right)+ \\
+\int_{-b_{0}}^{b_{0}} 2 \int_{\phi_{0}}^{\pi} A \operatorname{ch}\left(a_{0} \alpha_{1}^{\prime}\right) \cos \phi \cdot R_{0} d \phi d \alpha_{1}^{\prime}=0,
\end{gathered}
$$

або перепишемо у вигляді

$$
+2 A R_{0} \int_{-b_{0}}^{b_{0}} \operatorname{ch}\left(a_{0} \alpha_{1}^{\prime}\right) d \alpha_{1}^{\prime} \int_{\phi_{0}}^{\pi} \cos \phi d \phi=0 .
$$

Взявши інтеграли, отримаємо вираз

$$
-2 N_{0} \sin \phi_{0}-\frac{2 A R_{0}}{a_{0}} \operatorname{sh}\left(a_{0} b_{0}\right) \cdot 2 \sin \phi_{0}=0 \text {. }
$$

За отриманим виразом (2) знаходимо сталу $A$

$$
A=-\frac{N_{0} a_{0}}{2 R_{0} \operatorname{sh}\left(a_{0} b_{0}\right)} .
$$

Тоді контактний тиск, відповідно до залежності (1), буде становити

$$
q_{H}\left(\alpha_{1}^{\prime}, \alpha_{2}\right)=-\frac{N_{0} a_{0}}{2 R_{0} \operatorname{sh}\left(a_{0} b_{0}\right)} \operatorname{ch}\left(a_{0} \alpha_{1}^{\prime}\right),
$$

де $\phi_{0} \leq \phi \leq \pi$.

Аналізуючи розподіл контактного тиску, максимальне значення досягається на краях смуги контакту при $\alpha_{1}^{\prime}= \pm b_{0}$

$$
q_{\text {max }}=-\frac{N_{0} \cdot a_{0} \cdot \operatorname{ch}\left(a_{0} b_{0}\right)}{2 R_{0} \operatorname{sh}\left(a_{0} b_{0}\right)} .
$$

3 іншого боку, якщо припустити, що контактний тиск буде постійним по ширині дії бандажа, то потрібно переходити до границі в (4) при $a_{0} \rightarrow$ 0 , матимемо

$$
q_{H}\left(\alpha_{1}^{\prime}, \alpha_{2}\right)=-\frac{N_{0}}{2 R_{0} b_{0}} .
$$

Якщо припустити, що контактний тиск між обичайкою бака та бандажем змінюється за гіперболічним косинусом по ширині та тригонометричним косинусом по довжині, матимемо

$$
q_{H}\left(\alpha_{1}^{\prime}, \alpha_{2}\right)=\operatorname{Ach}\left(a_{0} \alpha_{1}^{\prime}\right) \cos \left(\frac{\pi}{2}-\phi+\phi_{0}\right)
$$

де $-\phi_{0} \leq \phi \leq \phi_{0}$

Такий випадок $€$ характерним, якщо для кріплення бака застосовується бандаж малого кута обхвату, тобто $\phi_{0}>\pi / 2$.

Для тригонометричної функції аргументи вибрано з умови

$$
\left.q\left(\alpha_{1}^{\prime}, \alpha_{2}\right)\right|_{\phi=\phi_{o}}=0 .
$$

Процедура віднаходження сталої $A €$ аналогічною до попереднього випадку. Проектуємо всі діючі сили на бандаж на вертикальну вісь, отримаємо

$$
\begin{gathered}
-2 N_{0} \cos \left(\phi_{0}-\frac{\pi}{2}\right)+ \\
+2 A R_{0} \int_{0}^{b_{0}} \operatorname{ch} a_{0} \alpha_{1}^{\prime} d \alpha_{1} \times \\
\times 2 \int_{\phi_{0}}^{\pi} \cos \left(\frac{\pi}{2}-\phi+\phi_{0}\right) \cos \phi d \phi=0 .
\end{gathered}
$$

Опускаючи проміжні викладки, отримаємо вираз для сталої $A$

$$
A=-\frac{N_{0} a_{0}}{R_{0}\left(\pi-\phi_{0}\right) \operatorname{sh}\left(a_{0} b_{0}\right)} .
$$

Враховуючи (9), вираз контактного тиску (7) перепишемо

$$
\begin{gathered}
q_{H}\left(\alpha_{1}^{\prime}, \alpha_{2}\right)= \\
=-\frac{N_{0} a_{0}}{R_{0}\left(\pi-\phi_{0}\right) \operatorname{sh}\left(a_{0} b_{0}\right)} \times \\
\times \operatorname{ch}\left(a_{0} \alpha_{1}^{\prime}\right) \sin \left(\phi-\phi_{0}\right),
\end{gathered}
$$

де $\phi_{0} \leq \phi \leq 2 \pi-\phi_{0}$.

Як частковий випадок можна прийняти, що $\phi_{0}=\pi / 2$, то вираз (10) прийме вигляд

$$
q_{H}\left(\alpha_{1}^{\prime}, \alpha_{2}\right)=\frac{-2 N_{0} a_{0}}{R_{0} \cdot \pi \cdot \operatorname{sh}\left(a_{0} b_{0}\right)} \operatorname{ch}\left(a_{0} \alpha_{1}^{\prime}\right) \cos \phi .
$$

Максимальне значення контактного тиску дотягається у точках $\alpha_{1}^{\prime}= \pm b_{0}, \phi=\pi$

$$
q_{\max }=\frac{-2 N_{0} a_{0} \operatorname{ch}\left(a_{0} b_{0}\right)}{R_{0} \cdot \pi \cdot \operatorname{sh}\left(a_{0} b_{0}\right)} .
$$

Якщо вважати, що контактний тиск $є$ сталим по ширині $2 b_{0}$ дії бандажа та вздовж всієї довжини $2 R_{0}\left(\pi-\phi_{0}\right)$, то запишемо

$$
q_{\mathrm{H}}\left(\alpha_{1}^{\prime}, \alpha_{2}\right)=A
$$

де $\phi_{0} \leq \phi \leq 2 \pi-\phi_{0}$.

Проектуючи сили, що діють на бандаж, на вертикальну вісь, одержимо

$$
\begin{gathered}
-2 N_{0} \cos \left(\frac{\pi}{2}-\phi_{0}\right)+ \\
+\int_{-b_{0}}^{b_{0}} 2 \int_{\phi_{0}}^{\pi} A \cos \phi \cdot R_{0} d \phi d \alpha_{1}^{\prime}=0,
\end{gathered}
$$

звідки 


$$
-2 N_{0} \sin \phi_{0}-4 b_{0} A R_{0} \sin \phi_{0}=0,
$$

тоді стала $A$

$$
A=-\frac{N_{0}}{2 R_{0} b_{0}} .
$$

Загальний вираз сталого в зоні контакту контактного тиску (13) прийме вигляд

$$
q_{H}\left(\alpha_{1}^{\prime}, \alpha_{2}\right)=-\frac{N_{0}}{2 R_{0} b_{0}},
$$

де $\phi_{0} \leq \phi \leq 2 \pi-\phi_{0}$.

Розглянемо ще один найбільш ймовірний закон розподілу контактного тиску бандажа на обичайку бака, який описується функцією, що є сталою за осьовою та змінною за коловою координатами.

$$
q_{H}\left(\alpha_{1}^{\prime}, \alpha_{2}\right)=A \cos \left(\frac{\pi}{2}-\phi+\phi_{0}\right)
$$

де $\phi_{0} \leq \phi \leq 2 \pi-\phi_{0}$.

Аналогічно, діючі зусилля на бандаж, проектуємо на вертикальну вісь

$$
\begin{gathered}
-2 N_{0} \cos \left(\phi_{0}-\frac{\pi}{2}\right)+2 A R_{0} \int_{0}^{b_{0}} d \alpha_{1}^{\prime} \times \\
\times 2 \int_{\phi_{0}}^{\pi} \cos \left(\frac{\pi}{2}-\phi+\phi_{0}\right) \cos \phi d \phi=0, \\
2 N_{0} \sin \phi_{0}+2 b_{0} R_{0} A\left(\pi-\phi_{0}\right) \sin \phi_{0}=0 .
\end{gathered}
$$

Звідси

$$
A=\frac{-N_{0}}{\left(\pi-\phi_{0}\right) b_{0} R_{0}} .
$$

Тоді вираз контактного тиску набуде вигляду

$$
q_{H}\left(\alpha_{1}^{\prime}, \alpha_{2}\right)=-\frac{N_{0}}{\left(\pi-\phi_{0}\right) b_{0} R_{0}} \sin \left(\phi-\phi_{0}\right),
$$

де $\phi_{0} \leq \phi \leq 2 \pi-\phi_{0}$.

Висновки. Таким чином було проведено моделювання дії бандажів на обичайку бака технологічної машини. Отримані залежності є однією із складових загального навантаження на обичайку бака при визначенні його напружено-деформованого стану. В ході локального дослідження отримано ряд моделей взаємодії бандажа з резервуаром: контактний тиск змінюється за гіперболічним косинусом вздовж ширини контакту бандажа та постійний по його довжині (4); контактний тиск змінюється за гіперболічним косинусом по ширині та тригонометричним косинусом по довжині (10); контактний тиск є сталим по ширині дії бандажа та вздовж всієї довжини контакту (15); контактний тиск бандажа на обичайку бака, який описується функцією, що є сталою за осьовою та змінною за коловою координатами (18).

Неописаною залишається «задана величина» $a_{0}$, значення якої має вплив на характер розподілу контактного тиску по ширині бандажа.
Ії̈ значення задають, виходячи із відомих конструктивних параметрів бандажів та обичайки бака, або визначають експериментально та вводять в розрахункову модель.

Отримавши кінцеві вирази для контактного тиску бандажа на обичайку бака, проводять процедуру розвинення даних функцій в тригонометричні ряди. Після чого їх інтегрують в загальну розрахункову модель для визначення напруженодеформованого стану обичайки бака технологічної машини.

\section{Література}

1. Рибак Т.І. Пошукове конструювання на базі оптимізації ресурсу мобільних сільськогосподарських машин. - Тернопіль, Збруч, 2002. - 330 с.

2. Рибак T.І. Особливості дослідження напружено-деформівного стану баків окремих машин для хімічного захисту / Т.І. Рибак, А.В. Бабій // Вісник Тернопільського державного технічного університету. - Тернопіль: ТДТУ, 2000. - Т.5(№4). - С. $10-15$.

3. Сухорольський М.А. Взаємодія циліндричної оболонки з опорами змінної товщини / М.А. Сухорольський, Т.І. Рибак, А.В. Бабій // Вісник Тернопільського державного технічного університету. - Тернопіль: ТДТУ, 2005. - Т.10 (№2). - С. 5 - 10.

4. Пелех Б.Л. Контактные задачи теории упругих анизотропных оболочек / Б.Л. Пелех, М.А. Сухорольский. - К. : Наук. думка, 1980. - 216 с.

5. Вікович І.А. Конструкції та динаміка штангових обприскувачів: Монографрія. - Львів: Видавництво Національного університету «Львівська політехніка», 2003. - 460 с.

\section{References}

1. Rybak T.I. Poshukove konstruiuvannia na bazi optymizatsii resursu mobilnykh silskohospodarskykh mashyn / Ternopil: Zbruch, 2002. 330 s.

2. Rybak T.I., Babii A.V. Osoblyvosti doslidzhennia napruzheno-deformivnoho stanu bakiv okremykh mashyn dlia khimichnoho zakhystu. Visnyk Ternopilskoho derzhavnoho tekhnichnoho universytetu. Ternopil: TDTU, 2000. T.5(№4). S. 10 - 15.

3. Sukhorolskyi M.A., Rybak T.I., Babii A.V. Vzaiemodiia tsylindrychnoi obolonky z oporamy zminnoi tovshchyny. Visnyk Ternopilskoho derzhavnoho tekhnichnoho universytetu. Ternopil: TDTU, 2005. T.10(№2). S. 5 - 10.

4. Pelekh B.L., Sukhorolskyi M.A. Kontaktnыe zadachy teoryy upruhykh anyzotropnokh obolochek / Kyiv : Nauk. dumka, 1980. 216 s.

5. Vikovych I.A. Konstruktsii ta dynamika shtanhovykh obpryskuvachiv: Monohrafiia / Lviv: Vydavnytstvo Natsionalnoho universytetu «Lvivska politekhnika», 2003. $460 \mathrm{~s}$. 


\title{
Аннотация
}

\section{Исследование прочности элементов конструкции функционально-транспортирующих мобильных средств}

\begin{abstract}
А.В. Бабий, М.В. Бабий
В данной работе проведен анализ конструктивных особенностей технологических машин, которые одной из своих функций имеют транспортировку воды или рабочих жидкостей. Проблема, которая часто возникает с такими транспортными средствами, - это механическое разрушение резервуара. В проведенном исследовании выбрана одна из групп таких машин, которые транспортируют цилиндрические резервуары. Особенностью конструкции представленных баков является то, что они установлены на опоры в виде ложементов и притянутые к ним гибкими бандажами. Чтобы выяснить причину разрушения указанных конструкций, сначала нужно проанализировать их напряженно-деформированное состояние. Этого можно достичь лишь в том случае, если является известной нагрузка на саму обечайку бака, то есть его цилиндрическую часть. За анализом литературных источников такая нагрузка может быть разделенной на несколько составляющих: от давления жидкости на стенки резервуара, сюда может добавляться еще избыточное давление; от действия опор (контактное давление); и аналогично от затягивания бандажей. Задача определения напряженно-деформированного состояния бака технологической машины достаточно сложна, ее решение должно быть поэтапным. Поэтому в данной работе рассматриваются математические модели нагрузки от затягивания бандажей при закрепленные бака к опорам как локальная задача относительно определения нагрузки в целом. Получив конечные выражения для контактного давления бандажа на обечайку бака, а также выражения, от других составляющих нагрузки, проводят процедуру развития данных функций в тригонометрические ряды. После чего полученные зависимости интегрируют в общую расчетную модель для определения напряженно-деформированного состояния обечайки бака технологической машины. А в конечном результате, это позволит выбирать удовлетворительный скоростной режим транспортировки данными машинами жидкости, учитывая динамику процесса.
\end{abstract}

Ключевые слова: транспортирование, бак, механическое разрушение, бандаж, контактное давление, математические модели.

\section{Abstract \\ Toughness research of construction elements of functional-transporting mobile devices}

\section{A.V. Babiy, M.V. Babii}

There is made an analysis of constructive peculiarities of technological machines in current work. This machines have such a function as water or work liquids transporting. The problem which often happens with those transport devices is tank mechanical destruction. It is choosen one of machine groups which transports cylinder tanks in conducted research. The peculiarity of presented tanks construction is their leaning on supports, which look like beddings, and fixed with flexible bandages. We have to analyze the tense deformation state to find a reason of current constructions destruction. We can make calculations if loading on side wall of tank (cylinder part of tank) is known. According to literature sources analysis the loading on cylinder side wall of tank can be divided by several components: liquid pressure on tank sides, can be added redundant pressure; from support interaction (contact pressure); and from tightens of bandages. Task determination of tense deformation state is rather difficult and its solution should be step by step. That's why, in current work, mathematical models of loading of bandages tightening while tank fixing to supports are shown as a local task for loading determination at all. The procedure of function transforming to trigonometric series conducts after receiving end equations of contact pressure of bandages on cylinder side wall of tank and equations of other loading components. Then held equations integrate to general calculation model for determination of tense deformation state of cylinder side wall of tank of technological machine. In the end result it will allow us to choose speed mode of liquids transporting considering the process dynamics.

Keywords: transporting, tank, mechanical destruction, bandage, contact pressure, mathematical models.

Бібліографічне посилання / Bibliography citation: Harvard

Babiy, A. and Babii, M. (2019) Toughness research of construction elements of functional-transporting mobile devices, Engineering of nature management, (3(13)), pp. 87 - 91.

Подано до редакції / Received: 07.05.2019 